\title{
Plasma Catecholamine Metabolites as Markers for Psychosis and Antipsychotic Response in Schizophrenia
}

\author{
Mary E. Kelley, M.S., Jeffrey K. Yao, Ph.D., and Daniel P. van Kammen, M.D., Ph.D.
}

The objective of this study was to determine the association between the patterns of change in the dopaminergic metabolite plasma homovanillic acid (HVA), the noradrenergic metabolite 3-methoxy-4hydroxyphenylglycol (MHPG), and psychosis following haloperidol withdrawal in schizophrenic patients. Weekly plasma measurements were obtained in 107 subjects with schizophrenia or schizoaffective disorder. Random

regression was used to control for individual variance while modeling metabolite changes over time and relationships with psychosis. Changes in plasma MHPG were not significantly associated with relapse or psychosis, while increased plasma HVA was found to be associated with relapse. Psychosis was correlated negatively with plasma HVA levels. The current analysis, controlling for individual variance, indicates that there is evidence for pharmacological effects on plasma HVA, but not plasma MHPG. In addition, these metabolites do not appear to be direct markers of psychosis, but may be associated with a compensatory response by the system to return to the steady state. [Neuropsychopharmacology 20:603-611, 1999] (C) 1999 American College of Neuropsychopharmacology. Published by Elsevier Science Inc.
KEY WORDS: Schizophrenia, Catecholamines, Homovanillic acid, Psychosis

The action of antipsychotic drugs on the dopamine system have led to many examinations of dopaminergic metabolites as possible markers for psychosis and antipsychotic response. However, it has also become clear that the noradrenergic system has extensive interactions with the dopamine system, and may also play a role in schizophrenia (Antelman and Caggiula 1977; Hornykiewicz 1982; van Kammen and Kelley 1991),

From the VA Pittsburgh Healthcare System (MEK, JKY, DPvK), Pittsburgh, Pennsylvania; and Western Psychiatric Institute and Clinic (JKY, DPvK), University of Pittsburgh, School of Medicine, Pittsburgh, Pennsylvania.

Address correspondence to: Mary Kelley, MS, GIM (13OU), VA Pittsburgh H.S., University Drive C, Pittsburgh, PA 15240.

Received March 27, 1998; revised July 24, 1998; accepted July 28, 1998. and may play a key role in psychotic relapse (Ko et al., 1988; van Kammen et al. 1989, 1994, 1996a). Interactions between the two systems have been well studied in the CSF and plasma of schizophrenic patients through their respective metabolites: the dopamine metabolite homovanillic acid (HVA) and the norepinephrine metabolite 3-methoxy-4-hydroxyphenylglycol (MHPG). Plasma HVA has been shown to reflect central or brain dopamine activity through studies in animals and humans (Bacopoulos et al. 1979; Kendler et al. 1982; Maas et al. 1993; Lambert et al. 1993; Amin et al. 1992), indicating that $11-35 \%$ of plasma HVA comes from the brain.

Several studies of schizophrenia have noted that the behavioral response to antipsychotic drugs (i.e., a decrease in psychosis levels) parallels a decrease in plasma HVA levels in schizophrenic patients over time (Pickar et al. 1984, 1986; Davidson and Davis 1988; Davila et al. 1988; Mazure et al. 1991; Sharma et al. 1989). Some studies have reported an initial increase in plasma HVA in the first week of antipsychotic drug 
treatment that also parallels the decrease in psychosis (Davila et al. 1988, 1995; Duncan et al. 1993), while others did not observe this effect (Pickar et al. 1986). Other studies of antipsychotic efficacy have focused on response status as the outcome measure and have shown that plasma HVA decreases were significant only in responders (Davidson et al. 1991a; Bowers et al. 1984; Chang et al. 1988; Van Putten et al. 1989). Some studies have shown that both plasma HVA and plasma MHPG decrease during neuroleptic treatment in those who respond favorably (Mazure et al. 1991; Bowers et al. 1984; Chang et al. 1990; Green et al. 1993).

Higher pretreatment plasma HVA has been shown to predict better response (Mazure et al. 1991; Bowers et al. 1984, 1986; Chang et al. 1990; Duncan et al. 1993; Scheffer et al. 1994; van Kammen et al. 1996b), and faster time to response (Koreen et al. 1994). In addition, several groups have studied both metabolites and found that while pretreatment plasma HVA predicts response, plasma MHPG does not (Mazure et al. 1991; Bowers et al. 1984, 1986; Chang et al. 1990). However, some studies have found that baseline plasma HVA did not predict response (Javaid et al. 1990; Petrie et al. 1990).

Drug withdrawal, and its effect on plasma MHPG and HVA levels, is less well studied. Studies have shown increases in plasma HVA following drug withdrawal (Pickar et al. 1986) specifically in those patients who experience an exacerbation (Beuger et al. 1996). Pickar et al. (1986) found that the increases in psychosis paralleled the increases in plasma HVA. Davidson et al. (1991b) observed no significant differences in baseline values of plasma HVA, but did observe a difference in change in plasma HVA from baseline in exacerbated patients, and a correlation between peak psychosis and peak plasma HVA during withdrawal. Studies of drugfree exacerbated patients have also reported positive associations between plasma HVA and positive symptoms (Maas et al. 1988). Studies examining both metabolites have shown differing results. Kirch et al. (1988) showed significant increases in plasma MHPG with a similar trend in plasma HVA after 6 weeks of withdrawal in those patients who relapsed but no significant associations with psychosis levels. Drug withdrawal studies in patients with tardive dyskinesia (TD), have shown increases in plasma HVA but not MHPG in relapsing patients (Glazer et al. 1989), while some have not shown significant changes in plasma HVA following drug withdrawal (Kirch et al. 1983).

Thus, there are conflicting reports in the literature regarding these plasma measures as markers of psychosis and response. We propose that this may be due to variation in the data, which may be better controlled for using alternative statistical methods. The majority of these studies were evaluated using endpoint analyses, i.e., means of the biochemical data computed from before and after treatment (or drug withdrawal) and then compared across groups. Some also assessed the changes in the biochemistry and correlated these with the change in behavioral measures. Some of these studies (Pickar et al. 1986; Kirch et al. 1983) attempted to characterize the response over time by plotting the plasma levels in the separate groups or correlating the psychosis ratings with plasma measures at each timepoint. Additional studies involved repeated measures ANOVA or MANOVA, attempting to define the pattern of means over time (Javaid et al. 1990; Davidson et al. 1991a,b). However, means compared at each timepoint are not sensitive to the individual's change over time. Given the wide variability in biochemical measures evident in schizophrenic subjects, it is unlikely that one function (e.g., a line or polynomial) could estimate the pattern of response in all individuals, as much be the case with ANOVA. If this was the case, each subject would have a similar intercept, or starting point, with only measurement error present. Analysis of group means over time assumes this similarity and cannot account for individual variation. Thus, a methodology that allowed for varying baseline values but still attempted to compare the response over time across subjects would be beneficial to the study of serial plasma metabolites in schizophrenia.

The use of random regression (Laird and Ware 1982) provides a solution by allowing the coefficients of the regression equation to be "random" or computed for each subject (Gibbons et al. 1993). In addition to allowing more of the variance to be modeled rather than assumed to be similar across subjects, random regression also provides a solution to the problem of missing data. Because individual effects are inherently part of the model, a model can be computed regardless of how many observations each subject has or whether or not the observations were measured at the same timepoints. However, this does assume that missing data are considered "ignorable" in that they depend only on the observed data used in the model (Gibbons et al. 1993; Laird 1988). In addition to these advantages, a regression setup allows us to test whether or not the changes in psychosis and the changes in plasma catecholamine metabolites follow the same linear pattern.

The purpose of the present study was to determine the association between the biochemical measures and psychosis ratings over time and whether these patterns differ between patients who did and did not experience an exacerbation of psychotic symptoms during the withdrawal period. To our knowledge, this is the first application of this type of analysis to the data on psychosis and monoamines in schizophrenic patients. We expected increases in plasma MHPG and HVA following drug withdrawal, and positive associations between psychosis and metabolite levels over time. 


\section{METHODS}

\section{Subjects}

The subjects were 107 male schizophrenic patients with a current diagnosis (DSM-IIIR) of chronic schizophrenia or schizoaffective disorder $(n=9)$ (APA 1987). The patients were on antipsychotic maintenance treatment and participated in the study after giving written informed consent. The risks of the study were discussed with the patient and significant others, and the patients were informed of the right to withdraw at any time during the study. Patients who met DSM-IIIR criteria for current alcohol or substance abuse/dependence were excluded at the time of the study, but were included if they had been in remission for at least 6 months. Diagnostic, clinical, and demographic data, as well as the ability to understand the risks involved, were examined at a consensus conference. The patients had mean ages of $36.9 \pm 8.1$ years (range 20-63), a mean age of onset of $23.5 \pm 5.1$ years (range 13-35), and a mean duration of illness of $13.5 \pm 7.1$ years (range $0.5-30$ ).

All subjects were put on a low monoamine and caffeine and alcohol-free diet upon admission, and their medication was converted to haloperidol for at least 3 months if they were not already being treated with haloperidol. Medications were administered in a doubleblind fashion. If benztropine mesylate ( $1-4 \mathrm{mg} /$ day) was given, this was discontinued at least 2 weeks prior to medication withdrawal. No other medications were given. The stabilization dose of haloperidol was $11.3 \pm$ $7.3 \mathrm{mg}$ / day (range 1-40). Identical looking placebo capsules replaced the haloperidol capsules overnight after research procedures were completed (van Kammen et al. 1989, 1995). After medication withdrawal, weekly plasma measures were obtained for 6 weeks in those who remained clinically stable or less if the subject met specific exacerbation criteria, at which time the last sample was taken and the patients were returned to their treatment regimens as clinically indicated. Relapse was monitored on a daily basis using the daily rating of the Bunney-Hamburg psychosis scale done by the nursing staff; this was done to prevent prolonged relapse. This provided an inherently unbalanced design, because the relapsed group had fewer observations per patient than the nonrelapsed group. Additional missing data resulted from refused or missed procedures (weekly rates between $4 \%$ and $15 \%$ ).

\section{Behavioral Ratings}

The same measure of psychosis was used to evaluate relapse status as well as track weekly psychosis during the drug withdrawal period. We used the 15-point global psychosis scale (Bunney and Hamburg 1963) which was rated daily by the nursing staff and weekly by the therapists. Raters were blind to the medication status. Baseline psychosis was determined as the mean of the daily ratings of the last week of haloperidol treatment; relapse was considered to have taken place when a score of 3 points above this baseline rating was sustained for 3 days. In addition, the drug-free rating was required to be 6 or higher, which assured a clear presence of psychotic symptoms. The therapists' ratings provided the weekly psychosis data for the purposes of the analysis. The Bunney-Hamburg scale of global psychosis is a measure of positive symptoms and the extent to which these symptoms interfere with daily functioning. It was chosen over BPRS items because it does not rely on specific symptoms which only some patients may have (e.g., grandiosity) and has more variance for the purpose of modeling. Inter-rater reliability was assessed biweekly and compiled every 6 months for the purpose of the raters; combined analysis of reliability across time produced an intercorrelation coefficient of 0.92 for the Bunney-Hamburg psychosis item. Of the 107 subjects, 54 met relapse criteria, 53 did not. Relapsed patients were drug free for $25 \pm 12$ days (range 5-50 days), while nonrelapsed patients were drug free for 6 weeks.

\section{Blood Draws}

Blood draws for plasma were performed at 8:00 a.m., with the subject remaining at bed rest, fasting and nonsmoking from 11:00 p.m. the previous evening until the completion of the procedure. Samples were stored at $-80^{\circ} \mathrm{C}$ until the time of the assay. Patients were not treated with debrisoquin, which has been shown to decrease the peripheral contribution to plasma HVA (Maas et al. 1988, 1993; Swann et al. 1980; Davidson et al. 1987a; Kopin et al. 1988; Duncan et al. 1993). However, the low-monoamine diet, minimization of physical activity, and fasting prior to the blood draw used in this study has been shown to reduce statistical effects on plasma HVA levels (Davidson et al. 1987b).

\section{Assay for Plasma HVA and MHPG}

The procedure for simultaneous extraction of plasma HVA and MHPG is a modified method of Gerhardt et al. (1986). First, $500 \mu \mathrm{L}$ of plasma sample is deproteinized through an Amicon MPS-1 micropartition system. Second, deproteinized plasma containing MHPG and HVA (pMHPG and pHVA) is extracted into ethyl acetate saturated with $\mathrm{NaCl}$. After evaporation of the ethyl acetate with $\mathrm{N}_{2}$, MHPG and HVA are reconstituted with $0.1 \mathrm{M} \mathrm{HClO}_{4}$, which contains $8 \mathrm{ng}$ of internal standard (DHBA). Consequently, $50 \mu \mathrm{L}$ of the solution is injected into reversed-phase HPLC with EC detection. Intra-assay coefficients of variation were found to be 
$10.07 \%$ for HVA at a concentration of $152.82 \mathrm{pmol} / \mathrm{ml}$, and $4.95 \%$ for MHPG at a concentration of $60.02 \mathrm{pmol} /$ $\mathrm{ml}$. Inter-assay coefficients of variation were found to be $10.39 \%$ for HVA at a concentration of $152.82 \mathrm{pmol} /$ $\mathrm{ml}$, and $6.62 \%$ for MHPG at a concentration of 60.02 $\mathrm{pmol} / \mathrm{ml}$. Repeated measures were assayed in the same run for each individual patient.

\section{Statistics}

Because we wanted to use the random intercept capabilities of the model to allow for variation in the plasma measures, plasma MHPG and plasma HVA were modeled separately as dependent variables in each case. In addition, this allowed for model fit estimations of the pattern of change in plasma measures following haloperidol withdrawal. Relapse, time drug free, and psychosis were fit as predictor (independent) variables. Relapse was represented using an indicator variable and the model was fit with no intercept to provide unique estimates and significance tests for each group. Although the missing data in the relapsers were inherent to the design, this is accounted for in the analysis through the inclusion of the grouping variable, which allows the missing data in the relapsers to be "ignorable" as defined by Laird (1988) and also allows for comparison across groups. In addition "time drug free" is represented in the analysis through the use of the "time" variable, which is measured in weeks (i.e., $0,1,2,3)$. Only drug-free data were modeled, as we were interested in the pattern of change drug free rather than the initial withdrawal effect. The procedure was performed in SAS using PROC MIXED (SAS Institute Inc. 1992) with restricted maximum likelihood (REML) estimation.

\section{Autocorrelation}

One of the foremost concerns in the analysis of repeated measures is the lack of independence, and controlling for this source of variance when modeling covariates. SAS PROC MIXED provides the ability to apply autocorrelation to the errors computed by the model and a test of whether this improves model fit. Thus, each model was fit with and without first-order autocorrelation in the error structure [AR (1)] to see if this additional model component improved the fit of the data.

\section{RESULTS}

Plotting the raw data illustrates the variance considerations in an analysis of patterns of change (Figure 1) (all plots not shown for brevity). Each random regression model was computed to determine if plasma HVA or plasma MHPG measures were significantly associated with psychosis over time. Psychosis is thus a timedependent covariate, rather than a baseline prediction score.

The model of plasma HVA revealed no significant change in plasma HVA over time in patients who did not relapse, and a steady increase in patients who did relapse (Figure 2). Psychosis was only a significant predictor of plasma HVA in the relapsed group, and was negatively associated with psychosis levels (Table 1). Thus, the data indicates that although there was an overall increase in plasma HVA levels in the relapsed group, higher psychosis levels were associated with lower plasma HVA levels at each specific timepoint. This apparent contrast in association with plasma HVA between relapse and psychosis is possible because psy-

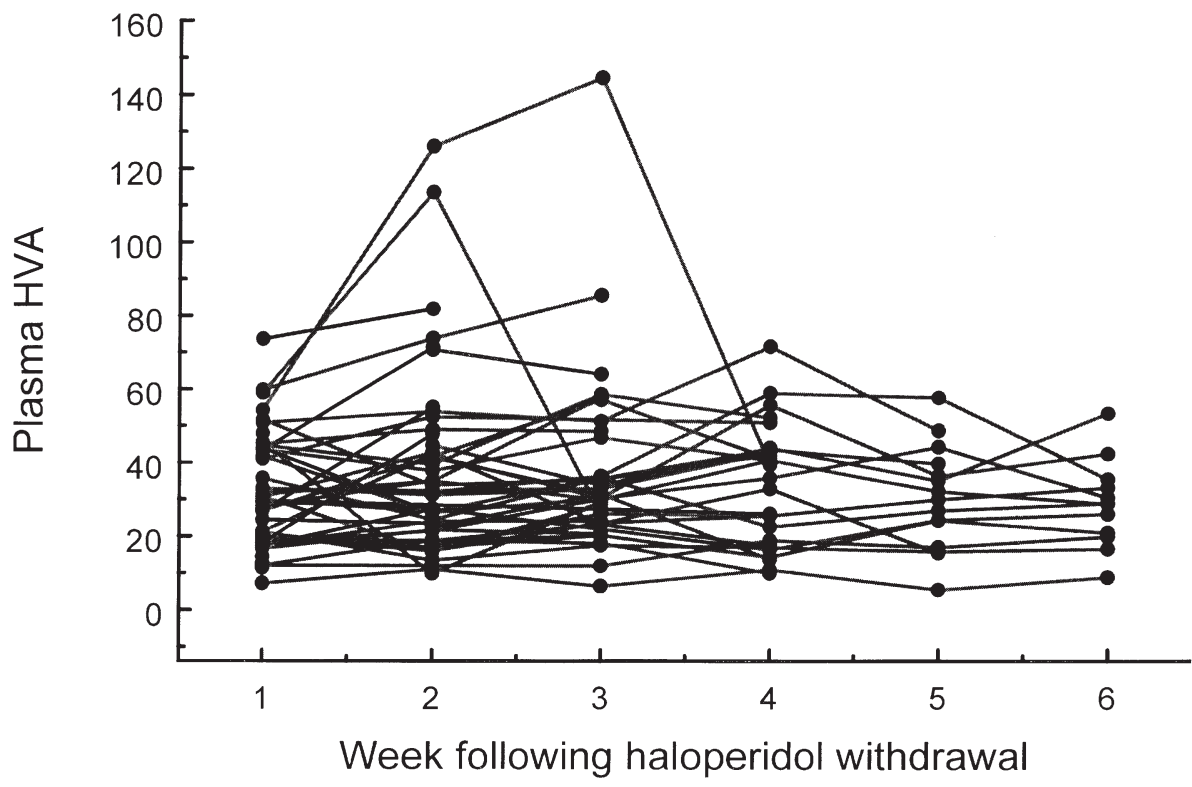

Figure 1. Individual patterns of plasma HVA following haloperidol withdrawal (relapsers only). (Plasma HVA measured in pmol/ $\mathrm{ml}$; Graph of the raw data emphasizes the large range of values across subjects.) 


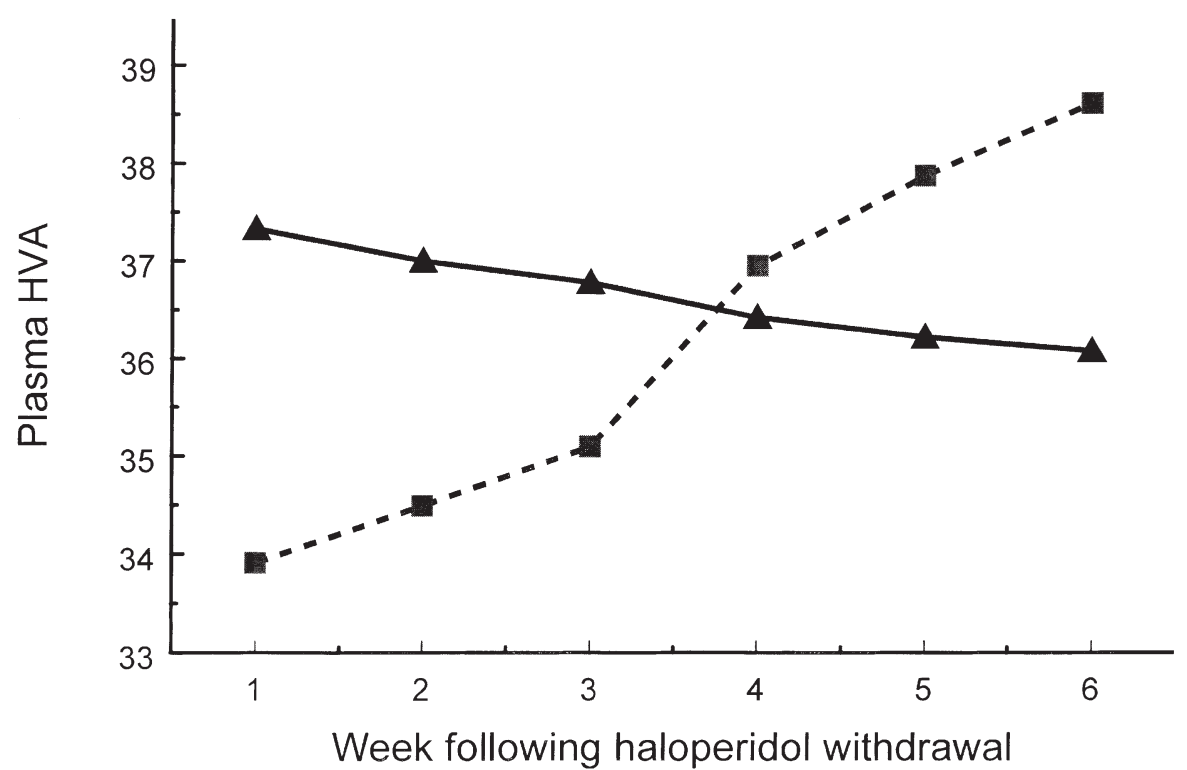

Figure 2. Plasma HVA following haloperidol withdrawal. Fitted regression lines given random intercept (different for each subject). (Predicted change in plasma HVA following haloperidol withdrawal; computed at mean levels of psychosis (Bunney and Hamburg, 1963; Range 1-15) at each timepoint for each group separately: Relapsers: 6.5, 7.3, 8.1, 7.8, 8.3, 9; Nonrelapsers: 5.1, 4.9, 5.0, 4.7, 4.8, 5.2 口- $\mathbf{\square} \mathbf{\square}$ relapsers; $\boldsymbol{\Delta}-\mathbf{\Delta}-\boldsymbol{\Delta}$ nonrelapsers; lines represent the "average" subject for that group, individuals may have lower or higher values depending on the intercept.) chosis is a time-dependent covariate, while relapse status is not. Thus, the two effects have opposite effects on the plasma HVA levels, indicating a possible regulatory mechanism. Adding a first-order autoregressive error structure to the plasma HVA model did not improve model fit (autocorrelation coefficient 0.04, $\mathrm{Z}=0.60, p=\mathrm{ns}$ ).

Plasma MHPG showed no change over time in relapsed patients, and a significant linear decrease in patients who did not relapse (Figure 3). Testing of psychosis as a predictor showed no significant associations with change in plasma MHPG over time for either group of patients. An autocorrelation coefficient was fit, which was shown to be significant, thus the final model described includes the autocorrelation term in the estimates (Table 2).

\section{DISCUSSION}

Previous data of medication treatment or withdrawal have suggested that levels of catecholamines and their metabolites, specifically HVA and MHPG, may reflect antipsychotic effects of agents such as haloperidol. One of the key issues dealt with in this study, which has plagued both the relationships investigated here as well as comparison of these metabolites with control subjects, is the enormous variance associated with these measures, particularly in schizophrenic patients. The analysis used here allows the baseline plasma level (week 1 drug free) to be different for each subject, and then further tests to see if the pattern of change over time is then similar across patients.

Table 1. Model for Plasma HVA: $\beta$ Coefficients and Significance ( $p$-values)

\begin{tabular}{|c|c|c|c|}
\hline & Relapsers & \multicolumn{2}{|c|}{ Nonrelapsers } \\
\hline $\begin{array}{l}\text { Baseline (week 1) plasma HVA + } \\
\text { individual offset (range) }{ }^{a}\end{array}$ & 17.22-90.84 & \multicolumn{2}{|c|}{$14.62-91.77$} \\
\hline Rate of increase in plasma HVA & $\begin{array}{l}1.56 \\
0.0383\end{array}$ & \multicolumn{2}{|c|}{$\begin{array}{l}-0.26 \\
\text { NS }\end{array}$} \\
\hline $\begin{array}{l}\text { Association between plasma } \\
\text { HVA and psychosis }(t)\end{array}$ & $\begin{array}{l}-1.23 \\
0.0404\end{array}$ & \multicolumn{2}{|c|}{$\begin{array}{l}0.353 \\
\text { NS }\end{array}$} \\
\hline Model statistics & Estimate & $\mathbf{Z}$ & $p$ \\
\hline $\begin{array}{l}\text { Random intercept variance } \\
\text { Residual variance }\end{array}$ & $\begin{array}{l}248.34 \\
130.61\end{array}$ & $\begin{array}{c}6.30 \\
13.41 \\
\chi_{(d f=1)}^{2}\end{array}$ & $\begin{array}{l}.0001 \\
.0001\end{array}$ \\
\hline Model likelihood ratio & & 259.32 & $<.0005$ \\
\hline
\end{tabular}




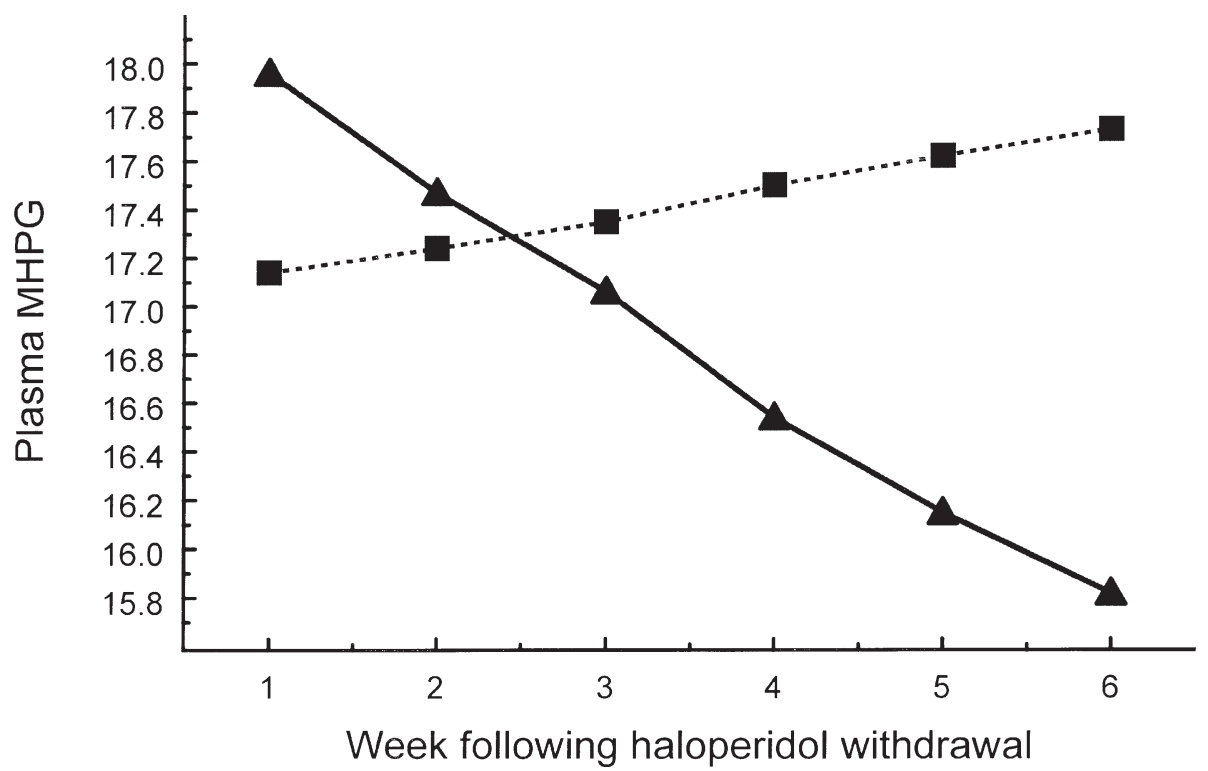

Figure 3. Plasma MHPG following haloperidol withdrawal. Fitted regression lines given random intercept (different for each subject). (Predicted change in plasma MHPG following haloperidol withdrawal computed at mean levels of psychosis (Bunney and Hamburg, 1963; Range 1-15) at each timepoint for each group separately: Relapsers: $6.5,7.3,8.1,7.8$, 8.3, 9; Nonrelapsers: 5.1, 4.9, 5.0, 4.7, 4.8, 5.2 - $\mathbf{\square}$ - - relapsers; $\boldsymbol{\Delta}$ $\boldsymbol{\Delta}-\boldsymbol{\Delta}$ nonrelapsers; lines represent the "average" subject for that group, individuals may have lower or higher values depending on the intercept.)

Allowing for this individual variance, we found linear increases in plasma HVA in relapsing patients only, and linear decreases in plasma MHPG in patients who did not relapse. Thus, our study verified increases in plasma HVA as a marker for relapse and possibly antipsychotic response, but did not confirm a similar effect on plasma MHPG levels. These results provide evidence that psychosis may be the result of a failed compensatory mechanism in the dopamine system, as originally proposed by Friedhoff (1986). Successful maintenance of the steady state of plasma HVA levels is visible in patients who did not relapse (Figure 2). These observations may also provide support for Bleuler's (Bleuler 1911; Rieder 1974) original hypothesis that psy- chosis is a secondary effect to the main disorder, which in this case would be the failed homeostasis of the dopamine system as indicated by the plasma HVA levels. These results are unique to this study due to the inclusion of a large number of drug-free non-exacerbated patients, which provided us with a comparison group for the assessment of the dopamine dynamics associated with relapse.

In contrast, associations with psychosis were different than hypothesized. Despite the fact that plasma HVA levels increased over time in the relapsed patients, higher psychosis levels were associated with lower plasma HVA levels at each timepoint. It is important to note that this is the case in the relapsed group

Table 2. Model for Plasma MHPG: $\beta$ Coefficients and Significance ( $p$-values)

\begin{tabular}{|c|c|c|c|}
\hline & Relapsers & \multicolumn{2}{|c|}{ Nonrelapsers } \\
\hline $\begin{array}{l}\text { Baseline plasma MHPG }+ \\
\quad \text { individual offset (range) }{ }^{a}\end{array}$ & $9.27-28.92$ & \multicolumn{2}{|c|}{$7.2-39.33$} \\
\hline Rate of increase in plasma MHPG & $\begin{array}{l}0.143 \\
\text { NS }\end{array}$ & \multicolumn{2}{|c|}{$\begin{aligned}-0.433 \\
0.0143\end{aligned}$} \\
\hline $\begin{array}{l}\text { Association between plasma } \\
\text { MHPG and psychosis }(t)\end{array}$ & $\begin{array}{c}-0.047 \\
\text { NS }\end{array}$ & \multicolumn{2}{|c|}{$\begin{array}{l}0.298 \\
\text { NS }\end{array}$} \\
\hline Model statistics & Estimate & $\mathbf{Z}$ & $p$ \\
\hline $\begin{array}{l}\text { Random intercept variance } \\
\text { Residual variance } \\
\text { Autocorrelation coefficient }\end{array}$ & $\begin{array}{r}35.31 \\
21.61 \\
0.14\end{array}$ & $\begin{array}{r}6.01 \\
11.12 \\
1.90 \\
\chi^{2}(d f=1)\end{array}$ & $\begin{array}{l}.0001 \\
.0001 \\
.0569\end{array}$ \\
\hline Model likelihood ratio & & 272.2 & $<.0005$ \\
\hline
\end{tabular}


only. The data may indicate that psychosis, in this group, is working against the relapse effect in an attempt to regulate the system. However, the attempt fails because the relapsing patients' dopamine continues to increase despite this fact. This seemingly paradoxical observation may reveal evidence that psychosis itself may have dopamine-reducing effects similar to that found with repeated stress in animal experiments (Friedhoff et al. 1995). If this is the case, psychosis may not only be a marker of the dysregulation of the dopamine system, but also a compensatory mechanism, which attempts to correct the dysregulation as well.

When combined, these findings would indicate that both metabolites are of interest when discussing pharmacological effects, but that direct correlations with psychosis may not be consistent across samples if the samples contained a varying mixture of relapsing and stable patients. This may explain why in many studies pharmacological effects were observed, but direct correlations with psychosis were not (Duncan et al. 1993; Van Putten et al. 1989; Scheffer et al. 1994; Koreen et al. 1994; Javaid et al. 1990; Petrie et al. 1990; Newcomer et al. 1992; Labarca et al. 1993; Sumiyoshi et al. 1997; Sharma et al. 1991).

The current analysis shows that time-specific correlations can be misleading when individual effects are not accounted for or if missing data are left out of the analysis, as must be done with ANOVA. Also, the fact that the nonrelapsed patients have different patterns of change in these metabolites following drug withdrawal implies that pharmacological effects on these metabolites are not the same for all patients. In addition, these measures are probably not direct markers of psychosis, given that levels of psychosis vary even within the nonrelapsed group.

We propose that higher plasma HVA is not necessarily associated with higher psychosis levels at any particular timepoint, but that it is associated with the range or possibly the peak of psychosis levels. Davidson et al. (1991b) took this approach with their ANOVA analysis of drug-free patients and found that peak plasma HVA levels were more highly associated with peak behavior than time-specific associations. If this is indeed the case, this would tie together the state-dependent (one timepoint) associations with behavior found in the literature with evidence that a trait (possibly genetic) component has also been found with these levels (Siever et al. 1991; Amin et al. 1997).

Finally, it should be noted that the modeling of individual effects makes intuitive sense in the study of schizophrenia as a whole because of the large variance between subjects on almost any biochemical or behavioral measure. From the range of intercepts given in Figure 1, it can be seen that an overall pattern in the metabolite levels over time might not have been identified if the model did not allow for different starting points.
Thus, inter-assay variability (i.e., lower or higher values due to different standard curves) would not reduce the chances for finding an overall effect as long as all samples for a subject were run in the same assay, as was the case in this study. Similarly, covariates which would be considered to raise or lower overall levels, such as age or chronic drug treatment, would not need to be controlled for because what is tested is the pattern and not the absolute levels. Thus, whether the variability is inherent to the disease or a methodological side effect, true patterns can be identified using this methodology.

\section{SUMMARY}

The current study supports the notion that although patterns of association exist between catecholamine metabolite levels and psychosis; individual effects and methodological constraints may make them more difficult to define. In addition, time-specific correlations may give misleading information, which is different from the overall effect, especially in the case of drug withdrawal. Further examination of the nature of dopamine dynamics in schizophrenia should take advantage of the modeling of individual effects in further investigations into the relationships with behavior.

\section{ACKNOWLEDGMENTS}

The authors thank the staff and patients of the Schizophrenia Research and Treatment Unit, VA Pittsburgh Healthcare System, for their support and dedication. Funding for this work was provided by the VA Merit Review Board, NIMH R01 MH44841, and the Bataan and Corregidor Medical Fund, Inc. Partial theory and data analysis was presented as part of a master's thesis (MK) at the Department of Biostatistics, University of Pittsburgh Graduate School of Public Health, Pittsburgh, PA.

\section{REFERENCES}

American Psychiatric Association (1987): Diagnostic and Statistical Manual of Mental Disorders, 3rd ed., Revised. Washington, DC, American Psychiatric Association

Amin F, Davidson M, Davis KL (1992): Homovanillic acid measurement in clinical research: A review of methodology. Schizophr Bull 18:123-148

Amin F, Siever LJ, Silverman J, Coccaro EF, Mitropoulou V, Trestman RL, Anderson GM, Davis KL (1997): Plasma HVA in schizotypal personality disorder. In Friedhoff AJ, Amin F (eds), Plasma Homovanillic Acid in Schizophrenia: Implications for Presynaptic Dopamine Dysfunction. Washington, DC, APA Press, pp 133-149

Antelman SM, Caggiula AR (1977): Norepinephrine-dopamine interactions and behavior. Science 195:646-653

Bacopoulos NG, Hattox SE, Roth RH (1979): 3,4-dihydroxyphenylacetic acid and homovanillic acid in rat plasma: 
Possible indicators of central dopaminergic activity. Eur J Pharmacology 56:225-236

Beuger M, van Kammen DP, Kelley ME, Yao J (1996): Dopamine turnover in schizophrenia before and after haloperidol withdrawal: CSF, plasma and urine studies. Neuropsychopharmacology 15:75-86

Bleuler E (1911): Dementia Praecox or the Group of Schizophrenias. Zinkin J (trans) (1950). New York, International University Press

Bowers MB Jr, Swigar ME, Jatlow PI, Hoffman F, Giocoechea N (1986): Early neuroleptic response in psychotic men and women: Correlation with plasma HVA and MHPG. Comprehensive Psychiatry 27:181-185

Bowers MB Jr, Swigar ME, Jatlow PI, Goicoechea N (1984): Plasma catecholamine metabolites and early response to haloperidol. J Clin Psychiatry 45:248-251

Bunney WE Jr, Hamburg DA (1963): Methods for reliable longitudinal observation of behavior. Arch Gen Psychiatry 9:280-294

Chang W-H, Chen T-Y, Lin S-K, Lung F-W, Lin W-L, Hu W-H, Yeh E-K (1990): Plasma catecholamine metabolites in schizophrenics: Evidence for the two-subtype concept. Biol Psychiatry 27:510-518

Chang W-H, Chen T-Y, Lee C-F, Hung J-C, Hu W-H, Yeh E-K (1988): Plasma homovanillic acid levels and subtyping of schizophrenia. Psychiatry Res 23:239-244

Davidson M, Losonczy MF, Mohs RC, Lesser JC, Powchik P, Freed LB, Davis BM, Mykytyn VV, Davis KL (1987a): Effects of debrisoquin and haloperidol on plasma homovanillic acid concentration in schizophrenic patients. Neuropsychopharmacology 1:17-23

Davidson M, Giordani AB, Mohs RC, Mykytyn VV, Platt S, Aryan ZS, Davis KL (1987b): Control of exogenous factors affecting plasma homovanillic acid concentration. Psychiatry Res 20:307-312

Davidson M, Davis KL (1988): A comparison of plasma homovanillic acid concentrations in schizophrenic patients and normal controls. Arch Gen Psychiatry 45:561-563

Davidson M, Kahn RS, Knott P, Kaminsky R, Cooper M, DuMont K, Apter S, Davis KL (1991a): Effects of neuroleptic treatment on symptoms of schizophrenia and plasma homovanillic acid concentrations. Arch Gen Psychiatry 48:910-913

Davidson M, Kahn RS, Powchik P, Warne P, Losonczy MF, Kaminsky R, Apter S, Jaff S, Davis KL (1991b): Changes in plasma homovanillic acid concentrations in schizophrenic patients following neuroleptic discontinuation. Arch Gen Psychiatry 48:73-76

Davila R, Manero E, Zumarraga M, Andia I, Schweitzer JW, Friedhoff AJ (1988): Plasma homovanillic acid as a predictor of response to neuroleptics. Arch Gen Psychiatry 45:564-567

Davila R, Gonzalez MA, Zumarraga M, Andia I, Guimon J, Silva RR, Friedhoff AJ (1995): Plasma prolactin and plasma homovanillic acid: Predictors of clinical response in schizophrenia. Biol Psychiatry 38:267-269

Duncan E, Wolkin A, Angrist B, Sanfilipo M, Wieland S, Cooper TB, Rotrosen J (1993): Plasma homovanillic acid in neuroleptic responsive and nonresponsive schizophrenics. Biol Psychiatry 34:523-528
Friedhoff AJ (1986): A dopamine-dependent restitutive system for the maintenance of mental normalcy. Ann NY Acad Sci 463:47-52

Friedhoff AJ, Carr KD, Uysal S, Schweitzer J (1995): Repeated inescapable stress produces a neuroleptic like effect on the conditioned avoidance response. Neuropsychopharmacology 13:129-138

Gerhardt GA, Drebing CJ, Freedman R (1986): Simultaneous determination of free homovanillic acid, (3-methoxy-4hydroxypheynl)ethylene glycol, and vanilmandelic acid in human plasma by high-performance liquid chromatography coupled with dual-electrode coulometric electrochemical detection. Anal Chem 58:2879-2883

Gibbons RD, Hedeker D, Elkin I, Waternaux C, Kraemer HC, Greenhouse JB, Shea MT, Imber SD, Sotsky SM, Watkins JT (1993): Some conceptual and statistical issues in analysis of longitudinal psychiatric data. Arch Gen Psychiatry 50:739-750

Glazer WM, Bowers MB Jr, Charney DS, Heninger GR (1989): The effect of neuroleptic discontinuation on psychopathology, involuntary movements, and biochemical measures in patients with persistent tardive dyskinesia. Biol Psychiatry 26:224-233

Green Al, Alam MY, Boshes RA, Waternaux C, Pappalardo KM, Fitzgibbon ME, Tsuang MT, Schildkraut JJ (1993): Haloperidol response and plasma catecholamines and their metabolites. Schizophr Res 10:33-37

Hornykiewicz O (1982): Brain catecholamines in schizophrenia-a good case for noradrenaline. Nature 299:484-486

Javaid JI, Sharma RP, Janicak PG, Davis JM (1990): Plasma HVA in psychiatric patients: Longitudinal studies. Psychopharmacol Bull 26:361-365

Kendler KS, Hsieh JY-K, Davis KL (1982): Studies of plasma homovanillic acid as an index of brain dopamine function. Psychopharmacol Bull 18:152-155

Kirch DG, Jaskiw G, Linnoila M, Weinberger DR, Wyatt RJ (1988): Plasma amine metabolites before and after withdrawal from neuroleptic treatment in chronic schizophrenic inpatients. Psychiatry Res 25:233-242

Kirch D, Hattox S, Bell J, Murphy R, Freedman R (1983): Plasma homovanillic acid and tardive dyskinesia during neuroleptic maintenance and withdrawal. Psychiatry Res 9:217-223

Ko GN, Jimerson DC, Wyatt RJ, Bigelow LB (1988): Plasma 3-methoxy-4-hydroxyphenylglycol changes associated with clinical state and schizophrenic subtype. Arch Gen Psychiatry 45:842-846

Kopin IJ, Bankiewicz KS, Harvey-White J (1988): Assessment of brain dopamine metabolism from plasma HVA and MHPG during debrisoquin treatment: Validation in monkeys treated with MPTP. Neuropsychopharmacology 1:119-125

Koreen AR, Lieberman J, Alvir J, Mayerhoff D, Loebel A, Chakos M, Amin F, Cooper T (1994): Plasma homovanillic acid levels in first-episode schizophrenia. Psychopathology and treatment response. Arch Gen Psychiatry 51:132-138

Labarca R, Silva H, Jerez S, Ruiz A, Forray MI, Gysling K, Andres ME, Bustos G, Castillo T, Hono J (1993): Differential effects of haloperidol on negative symptoms in 
drug-naive schizophrenic patients: Effects on plasma homovanillic acid. Schizophr Res 9:29-34

Laird NM, Ware JH (1982): Random-effects models of longitudinal data. Biometrics 38:963-974

Laird NM (1988): Missing data in longitudinal studies. Stat Med 7:305-315

Lambert GW, Eisenhofer G, Jennings GL, Esler MD (1993): Regional homovanillic acid production in humans. Life Sci 53:63-75

Maas JW, Contreras SA, Seleshi E, Bowden CL (1988): Dopamine metabolism and disposition in schizophrenic patients. Arch Gen Psychiatry 45:553-559

Maas JW, Contreras SA, Miller AL, Berman N, Bowden CL, Javors MA, Seleshi E, Weintraub S (1993): Studies of catecholamine metabolism in schizophrenia/psychosis-I. Neurospsychopharmacology 8:97-109

Mazure CM, Nelson JC, Jatlow PI, Bowers MB (1991): Plasma free homovanillic acid (HVA) as a predictor of clinical response in acute psychosis. Biol Psychiatry 30:475-482

Newcomer JW, Riney SJ, Vinogradov S, Csernansky JG (1992): Plasma prolactin and homovanillic acid as markers for psychopathology and abnormal movements during maintenance haloperidol treatment in male patients with schizophrenia. Psychiatry Res 41:191-202

Petrie EC, Faustman WO, Moses JA, Lombrozo L, Csernansky JG (1990): Correlates of rapid neuroleptic response in male patients with schizophrenia. Psychiatry Res 33:171-177

Pickar D, Labarca R, Doran AR, Wolkowitz OM, Roy A, Breier A, Linnoila M, Paul SM (1986): Longitudinal measurement of plasma homovanillic acid levels in schizophrenic patients. Correlation with psychosis and response to neuroleptic treatment. Arch Gen Psychiatry 43:669-676

Pickar D, Labarca R, Linnoila M, Roy A, Hommer D, Everett D, Paul SM (1984): Neuroleptic-induced decrease in plasma homovanillic acid and antipsychotic activity in schizophrenic patients. Science 225:954-957

Rieder RO (1974): The origins of our confusion about schizophrenia. Psychiatry 37:197-208

SAS Institute Inc (1992): SAS Technical Report P-229, SAS/ STAT Software: Changes and Enhancements, Release 6.07. Cary, NC, SAS Institute Inc.

Scheffer R, Diamond BI, Borison RL, Correnti EE, Mukherjee S (1994): Low plasma homovanillic acid (HVA) at the onset of psychosis (abstract). Biol Psychiatry 35:701-702
Sharma RP, Javaid JI, Pandey GN, Janicak PG, Davis JM (1991): Behavioral and biochemical effects of methylphenidate in schizophrenic and nonschizophrenic patients. Biol Psychiatry 30:459-466

Sharma RP, Javaid JI, Janicak PG, Comaty J, Davis JM (1989): Plasma and CSF HVA before and after pharmacological treatment. Psychiatr Res 28:97-104

Siever LJ, Amin F, Coccaro EF, Bernstein D, Kavoussi RJ, Kalus O, Horvath TB, Warne P, Davidson M, Davis KL (1991): Plasma homovanillic acid in schizotypal personality disorder. Am J Psychiatry 148:1246-1248

Sumiyoshi T, Hasegawa M, Jayathilake K, Meltzer HY (1997): Sex differences in plasma homovanillic acid levels in schizophrenia and normal controls: Relation to neuroleptic resistance. Biol Psychiatry 41:560-566

Swann AC, Maas JW, Hattox SE, Landis H (1980): Catecholamine metabolites in human plasma as indices of brain function: Effects of debrisoquin. Life Sci 27:1857-1862

van Kammen DP, Kelley M (1991): Dopamine and norepinephrine activity in schizophrenia: An integrative perspective. Schizophr Res 4:173-191

van Kammen DP, Peters JL, van Kammen WB, Nugent A, Goetz KL, Yao J, Linnoila M (1989): CSF norepinephrine in schizophrenia is elevated prior to relapse after haloperidol withdrawal. Biol Psychiatry 26:176-188

van Kammen DP, Ågren H, Yao JK, O'Connor DT, Gurklis JA, Peters JL (1994): Noradrenergic activity and prediction of psychotic relapse following haloperidol withdrawal in schizophrenia. Am J Psychiatry 151:379-384

van Kammen DP, Kelley ME, Gurklis JA, Gilbertson MW, Yao JK, Peters JL (1995): Behavioral vs. biochemical prediction of clinical stability following haloperidol withdrawal in schizophrenia. Arch Gen Psychiatry 52:673-678

van Kammen DP, Kelley ME, Gurklis JA, Gilbertson MW, Yao JK, Condray R, Peters JL (1996a): Predicting duration of clinical stability following haloperidol withdrawal in schizophrenic patients. Neuropsychopharmacology 14: 275-283

van Kammen DP, Kelley ME, Yao JK, Gilbertson MW, Gurklis JA, Inosaka T, Saito H, Peters JL, Sato M (1996b): Predicting haloperidol treatment response in chronic schizophrenia. Psychiatry Res 64:47-58

Van Putten T, Marder SR, Aravagiri M, Chabert N, Mintz J (1989): Plasma homovanillic acid as a predictor of response to fluphenzine treatment. Psychopharmacol Bull 1:89-91 